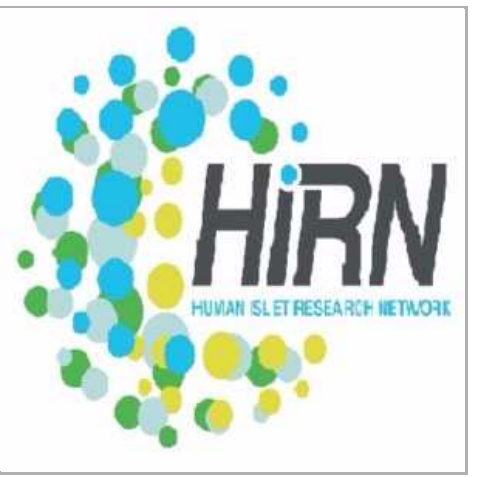

SEP 24, 2021

\title{
(3) Thymectomy procedure to remove native thymus of NSG mice
}

Mohsen Khosravi-

Maharlooei $^{1}$,

Markus Holzl ${ }^{1}$, Austin Chen ${ }^{1}$,

Megan Sykes ${ }^{1}$

${ }^{1}$ Columbia Center for Translational Immunology, Columbia University, New York

\section{Human Islet Research Network}

\section{open ठaccess}

DOI:

dx.doi.org/10.17504/protocol s.io.bvrhn536

Protocol Citation: Mohsen Khosravi-Maharlooei, Markus Holzl, Austin Chen, Megan Sykes 2021. Thymectomy procedure to remove native thymus of NSG mice. protocols.io

https://dx.doi.org/10.17504/p rotocols.io.bvrhn536

License: This is an open access protocol distributed under the terms of the Creative Commons Attribution License, which permits unrestricted use, distribution, and reproduction in any medium, provided the original author and source are credited

Protocol status: Working We use this protocol and it's working

Created: Jun 11, 2021

Note

\section{Corresponding Authors}

\section{Mohsen Khosravi-Maharlooei}

Email:mkm2182@cumc.columbia.edu

\section{Austin Chen}

Email: ac4274@cumc.columbia.edu

Tel: 425-283-6900

Last Modified: Sep 24, 2021

PROTOCOL integer ID: 50697 


\section{BEFORE START INSTRUCTIONS}

NSG mice older than 3-4 weeks could be thymectomized with this method. First, mice are weighed and anesthetized using ketamine $(100 \mathrm{mg} / \mathrm{kg}$, intraperitoneal) and xylazine (10 mg/kg, intraperitoneal). Surgeons wear a mask, head cover, clean lab coat and sterile gloves and the surgery is performed under aseptic conditions in a laminar hood to avoid contamination. As the NSG mice are immunodeficient, these measures are very important to prevent any infection.

The steps of the thymectomy surgery as shown in Figure 1 are detailed below.

1 The anterior neck is shaved and disinfected with betadine and $70 \%$ alcohol consisting of three alternate swabs followed by a final application of betadine solution. Limbs are gently restrained using rubber bands.

2 Using a pair of forceps, the skin at the junction of the neck and chest is grasped and a vertical midline incision is made with scissors. Alternatively, a scalpel blade may be used to make the incision. 1-2 drops of $2 \%$ lidocaine are applied on the incision site for local analgesia.

3 Using two pair of forceps, skin is gently detached from the connective tissues underneath.

4 The thyroid gland and surrounding connective and fat tissues are mobilized upward by blunt dissection using the forceps. The trachea becomes visible, although muscles are still superficial to it.

5 Muscles superficial to the trachea, including the sternocleidomastoid, sternohyoid and sternothyroid muscles are grasped with a pair of forceps.

6 Using the other pair of forceps, a space is made underneath the muscles by detaching them from the underlying tissues, which include the trachea.

7 While holding the muscles up with a pair of forceps, the sternal attachment site is cut using 
scissors. It is critical not to cut or damage the trachea itself.

8 The muscles that are now cut at their sternal end are pulled up. The trachea is now fully exposed.

9 Using a $0.8 \mathrm{~mm}$ curved Iris forceps (held in the left hand for right-handed people), the sternum is elevated. The surgeon should position him/herself in a way to be able to see into the mediastinum. Having a light source is recommended to increase the visibility. The thymus itself would not be visible yet at this step. A second $0.8 \mathrm{~mm}$ Iris forceps is inserted into the mediastinum (held in the right hand for right-handed people) while its prongs are in an open position and the curves are facing down. It should be inserted through for about $1 \mathrm{~cm}$. The forceps should be closed immediately and the tissue that is grasped by the forceps should be pulled out until it is visible. The thymus tissue will not be visible before it is grasped by the forceps. As the surgeon sees into the mediastinum, he/she will observe a dead-ended space. However, as the forceps with its prongs in an open position is further advanced through the mediastinum, the seemingly dead-ended space will open up and the forceps will pass through a hole. Immediately after passing through this hole, the forceps should be closed to grasp the thymus and it should be pulled out.

10 The right lobe of the thymus, which is at a superior position is usually grasped and pulled out by this step.

11 Using the forceps in the left hand, the right lobe of the thymus is re-grasped and gently pulled up and toward the left side, so that the left lobe of the thymus is also exposed.

12 Using the forceps in the right hand, the left lobe, which is usually at the inferior position, is grasped.

13 Thymic lobes are detached from the connective tissue by gently pulling them up. Sometimes it may be necessary to pass the thymic lobes to the other forceps and remove them by passing them repeatedly between the two pairs of forceps in the left and right hands. However, the thymic lobes should never be released, as they will go back to their original position and a second grab would increase the chance of pneumothorax and rupturing the vessels. This step should be 
performed in less than a minute. Performing this step quickly and acquiring experience will decrease the chance of failure and death. If this step is done quickly and the manipulation is minimum, the amount of air penetrating the thoracic cavity is negligible. Therefore, no ventilation will be necessary.

14 Immediately, the thyroid and the connective tissues are pulled down to cover the trachea and the mediastinum. Covering the site that was used to pull the thymus out will prevent air from entering into the mediastinal cavity and prevents pneumothorax.

15 The skin at both ends of the incision is grasped using both pairs of forceps to align the incision edges together.

16 The incision is closed using staples, which should be removed in 10 days. Mice are then placed in a cage on a heat mat to avoid hypothermia, with care not to overheat the animals. An analgesic such as buprenorphine $(0.1 \mathrm{mg} / \mathrm{kg}$, subcutaneous) should be administered prior to initiating the procedure and also every 8-12 hours up to 48 hours to minimize pain/distress. Also, administration of an antibiotic such as gentamicin $(0.5 \mathrm{mg} / \mathrm{ml}$ in sterile saline, $100 \mathrm{ul} / \mathrm{mouse}$, subcutaneous) will diminish the risk of infection.

\section{Figure 1. Different steps of the thymectomy surgery}



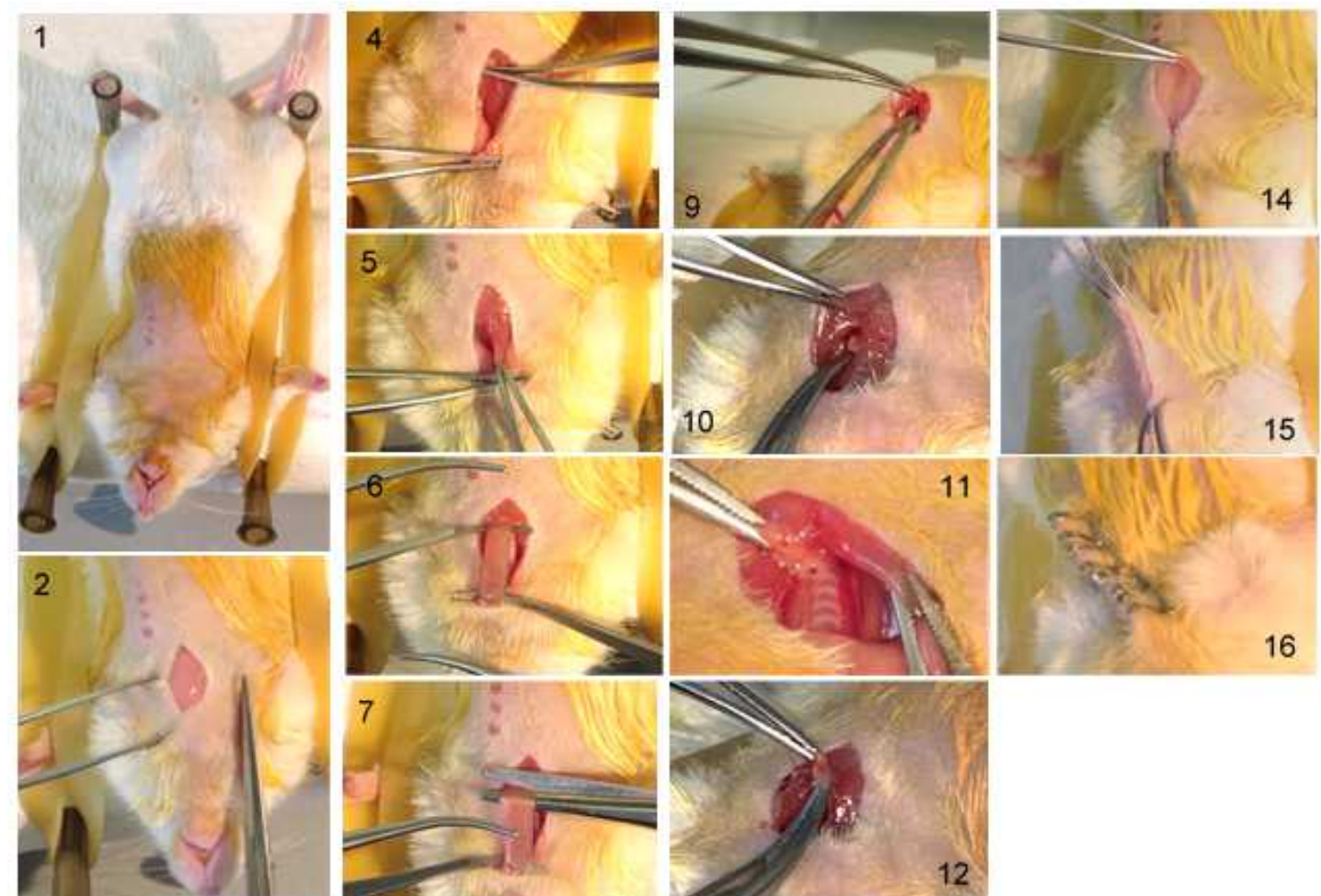

11
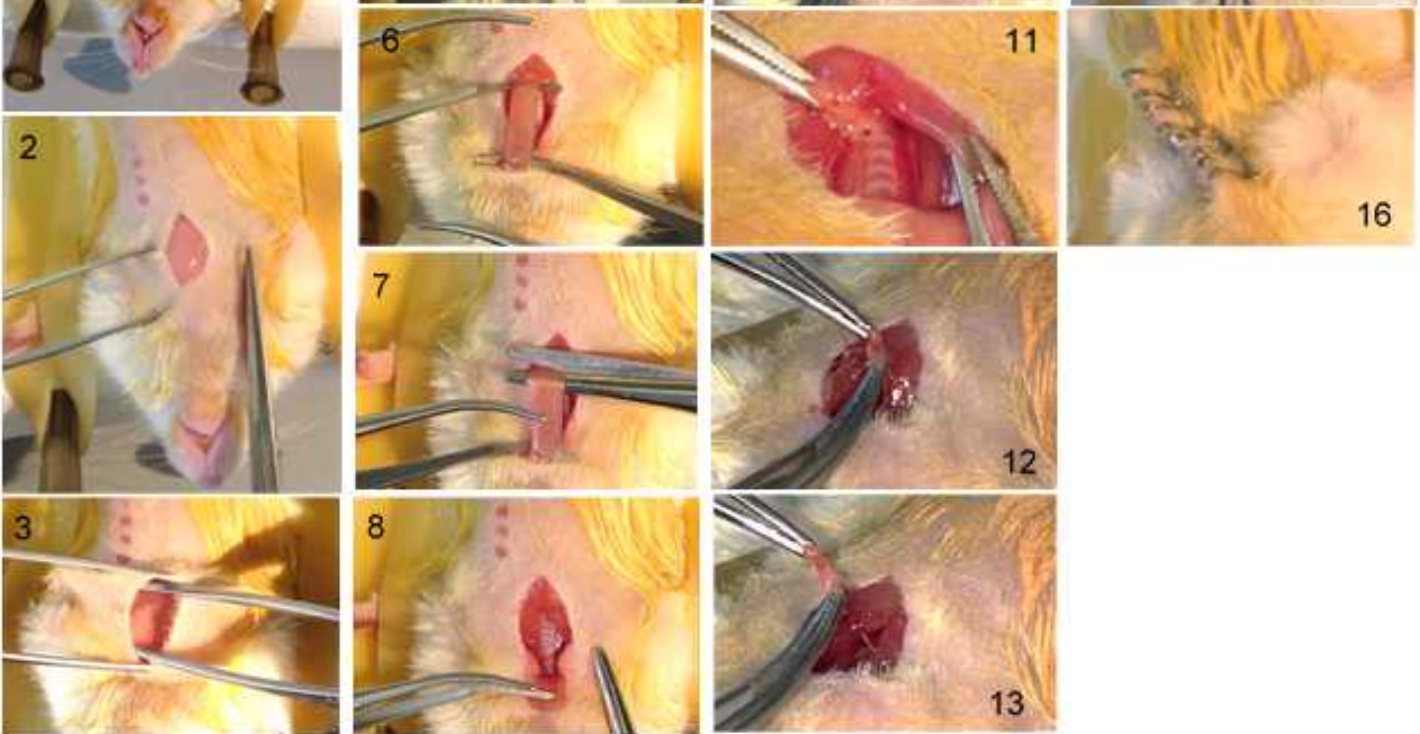